\title{
Um estudo sobre o papel da mulher na sociedade brasileira por meio de O Cravo e a Rosa e Coisa Mais Linda
}

\author{
A study about women role in brazilian society by O Cravo e a Rosa and Coisa Mais Linda \\ Maiara Leite* \\ Ana Carolina Silva**
}

Palavras chave:

Dominação masculina

O Cravo e a Rosa

Coisa Mais Linda

\begin{abstract}
Resumo: Este artigo pretende discutir se houve e, em caso positivo, quais foram as mudanças na sociedade brasileira em relação ao papel da mulher na sociedade, partindo da compreensão do feminismo como agente condutor das transformações sociais entre os períodos de 1920 e 1960. Para tanto, a pesquisa recorre às mídias como fonte principal e dentro desta, uma perspectiva analítica acerca da dominação masculina e o papel da mulher entre as décadas de 1920 e 1960 na sociedade brasileira. Isto, por meio da novela O Cravo e a Rosa (2000) da Rede Globo, e a série Coisa Mais Linda (2019) produzida pela Netflix.
\end{abstract}

Keywords:

Male Domination

O Cravo e a Rosa

Most Beautiful Thing

\begin{abstract}
This article intends to discuss whether there was and, if so, which were, the changes in brazilian society in relation to the role of women in society, starting from the understanding of feminism as a driving agent of social changes betwen the 1920's and the 1960's. Therefore, this research resorts to the midia as a main resource and as perspective about male domination and the woman role between the 1920's and 1960's in Brazilian society. The research is developed by the contribution of O Cravo e a Rosa (2000), Rede Globo production, and the tv show Coisa Mais Linda (2019) Netflix production.
\end{abstract}

Recebido em 20 de março de 2021. Aprovado em 06 de outubro de 2021.

\section{Introdução}

Este estudo, de caráter investigativo visa, sobretudo, dentro do campo da história cultural entender qual o papel da mulher na sociedade, de acordo com as obras O Cravo e a Rosa (2000-2001) e Coisa mais linda (2019), e do mesmo modo, discutir as - e se houve - mudanças no início do século XX, época em que as obras estão ambientadas. Dentre os períodos, portanto, é necessário discutir o papel do feminismo como movimento e como agente transformador do papel da mulher na sociedade brasileira, e analisar a dicotomia homem-mulher, cujo a percepção sobre a dominação masculina se torna importante na pesquisa.

\footnotetext{
* Professora da Secretaria de Educação do estado de São Paulo. Mestre em Planejamento Urbano e Regional e graduada em História pela Universidade do Vale do Paraíba. E-mail: maiarasanches@prof.educacao.sp.gov.br.

** Mestranda em Ciências Humanas e Sociais da Universidade Federal do ABC. Graduada em História pela Universidade do Vale do Paraíba. E-mail: alves.ana@ufabc.edu.br.
} 
Utilizar-se-á a obra de Pierre Bourdieu, "A Dominação Masculina" como principal fonte teórica no que se refere às relações sociais entre homens e mulheres, e desta interferência no babitus social. Portanto, Bourdieu (2012), possui relevância como principal referencial teórico dentro das representaçóes de gênero. Para todos os efeitos, o conceito de cultura aqui usado, está pautado na perspectiva apresentada por Clifford Geertz (2008, p. 10), em sua obra "A Interpretação das culturas", entendendo cultura como "um contexto, algo dentro do qual eles [os acontecimentos sociais, os comportamentos, as instituiçóes ou processos] podem ser descritos de forma inteligível”. Dessa forma, entende-se cultura como um emaranhado de símbolos produzidos socialmente, sendo possível estudá-la através de suas expressóes, tais como comportamentos, relaçóes sociais, discursos, etc. Em meio a esse aglomerado de símbolos, encontram-se aqueles que regulam as relaçôes sociais entre os gêneros e o que os caracterizam.

Para entender as falas das personagens e a representação destas em um tempo e um espaço específico, utilizar-se-á Michael Foucault (1996), como conceito fundamental. $\mathrm{O}$ autor entende o discurso como fonte de poder de uma sociedade ou um sujeito, seja simbolicamente ou mesmo, fisicamente. Desse modo, a dominação masculina na sociedade brasileira prescinde de um contexto e de um discurso de poder que permeia e rege a dinâmica social entre homem-mulher.

O estudo busca, por meio das fontes primárias, como a transcrição de falas, e análise de conteúdo entender e conceber a realidade de determinados sujeitos em seus respectivos tempos de ação. Nesta pesquisa, baseada em transcrições de falas presentes em obras de ficção, o objetivo é relacioná-las entre os períodos de 1920 e 1960, para entender o papel da mulher no babitus social.

A pesquisa justifica-se a partir da premência em se tratar da história das mulheres, e, consequentemente, da história das mulheres no Brasil. Isto é, o tema de gênero tem se desenvolvido em grande escala nas últimas décadas, todavia, é um tema que representa a história dos excluídos, além de estar pautado em inequidades sociais atuais. Para tanto, é necessário entender como e onde essas mulheres se situavam no início do século, assim como, de que maneira a luta e o feminismo contribuíram, à época, para mudanças posteriores, ainda que este não seja o objetivo do presente estudo.

Desse modo, organiza-se os subtópicos como parte da discussão que se inicia nas mudanças socioculturais em relação à mulher entre os séculos XIX e XX, até o momento em que os "ventos" e ideias feministas ganham voz no Brasil, no início do século $\mathrm{XX}$, e a maneira pela qual a mulher na sociedade brasileira reagiu à primeira onda feminista. Assim como, busca-se elaborar a relação entre a dominação masculina, por Bourdieu (2012) no habitus das relações sociais brasileiras, e consequentemente, por intermédio das obras $\mathrm{O}$ Cravo e a Rosa (2000) e Coisa mais linda (2019) discutir e compreender o retrato da sociedade patriarcal brasileira, e as dificuldades e relaçóes sociais de gênero entre os anos de 1920 e 1960.

\section{O papel da mulher no século XX}

Michelle Perrot (1988), em "Os excluídos da história", trabalha a relação entre as mulheres e o poder, e contempla a ideia de que tal palavra, ainda que possua alguns significados, necessariamente representa o masculino, uma vez que se refere às influências diversas, estas, realizadas para e por homens. A autora, em contraponto a definição, entende que

se elas não têm poder, têm, diz-se poderes. No Ocidente contemporâneo, investem no privado, no familiar e mesmo no social, na sociedade civil. Reinam no imaginário dos homens e preenchem suas noites e ocupam seus sonhos (PERROT, 1998, p. 167)

Tal relação entre poder e mulher é fundamental para conceber este estudo, pois, ao passo em que a história coloca esses indivíduos à margem de resoluçóes mais complexas, reservando-lhes somente o papel de esposa e mãe, o poder insurgente que as mulheres buscam por meio da conquista de direitos se revela amplo no que tange às vivências, e a consequente dominação masculina. A dicotomia homem-mulher, macho-fêmea foi recorrente no imaginário ocidental 
dos séculos XIX e XX, e essas relaçôes de dominação e de divisão marcadas entre territórios simbólicos permitidos e negados para ambos os sexos estabeleceu uma teia de conceitos, reforçados pela Igreja, que permearam o babitus das práticas sociais.

A história das mulheres foi construída em meio ao poder patriarcal, e sobretudo, à dominação da Igreja perante a sociedade e seus modos de vivenciar as relações (ARAÚJO, 1993). A ideia de que à mulher estavam reservados os espaços privados, os filhos e os afazeres domésticos enquanto aos homens os espaços públicos e as honras sociais perduraram séculos, tanto no Ocidente, quanto no Oriente (PRIORE, 1995). Estas práticas consideradas heteronormativas e patriarcais alijavam as mulheres de decisóes importantes, inclusive sobre elas mesmas, pois, seu destino estava ligado estritamente ao seu pai, em primeira instância, e após o casamento, ao seu marido (IDEM).

Desde a Revolução Francesa foi possível perceber, ainda que de forma pouco organizada, a mobilização das mulheres pelo direito à cidadania. Após a Primeira Guerra Mundial, o movimento de mulheres se organizou e se tornou mais visível na Europa, assim como, a ideia sobre as relaçôes de gênero, com efeito, o papel das mulheres na sociedade civil recebeu atenção. No entanto, foi com o movimento relacionado ao voto que as mulheres fizeram-se notar, no início do século XX. O movimento sufragista se espalhou pela Europa e pelos Estados Unidos, evidenciando a "primeira onda feminista”, isto é, a primeira manifestação notável e organizada das mulheres em busca de direitos (TBÉBAUD, 1993 PINTO, 2003).

$A$ relação entre mulher e trabalho se constituiu na Europa, no curso da Primeira Guerra Mundial, em que necessitavam da mão de obra feminina, e consequentemente, resultou em alguma "liberdade", pois, este foi o momento mais significativo até então em que houve valorização do trabalho feminino em favor da pátria. Por necessidade, a Guerra eliminou barreiras entre homens e mulheres, o que as levou para posições superiores, como de médicas e advogadas, na França. E em outros casos, em que mulheres trabalhavam em restaurantes, cafés; foi possível observar esses indivíduos em espaços públicos, sendo protagonistas (TBÉBAUD, 1993).
Por intermédio da Primeira Guerra as mulheres adquiriram algum poder, pelo menos, o de se sentirem importantes perante a sociedade patriarcal que guiava as relações sociais e matizava os lugares de homens e mulheres. Ou seja, com os efeitos da Guerra, a paisagem social se constituiu de maneira diferente em relação aos séculos XVIII e XIX, o que proporcionou não só o fortalecimento do Movimento Feminista, como a disseminação das ideias ao redor do mundo, com significativos ecos no Brasil.

\section{A dominação masculina no babitus das relaçôes sociais brasileiras}

Estudar o papel da mulher dentro da sociedade brasileira implica, necessariamente, em compreender como acontecem as relaçóes de gênero dentro dessa cultura.

Bourdieu (2012), em sua obra "A dominação masculina", investigou os símbolos que regulam as relações sociais entre os gêneros e o que os caracteriza em um contexto generificado, mas que se aplica ao brasileiro, e sua relação constituída histórica e socialmente. Para o autor, a disseminação destes símbolos se daria através de instituiçóes como Estado, Igreja, família, escola e os meios de comunicação, de forma a garantir a manutenção do sistema. A divisão dos sexos, pautada na diferença anatômica entre homem e mulher, compóe-se de um sistema infinito de oposiçôes homólogas: ativo/passivo, grande/pequeno, forte/fraco, dominação/submissão, homem/mulher, sendo expressa em instâncias objetivas (diferença anatômica, trabalho) e simbólicas (expresso através do habitus) (BOURDIEU, 2012).

Ao babitus masculino seriam designados os aspectos de poder dentro do sistema de oposição: força, grande, ativo, dominação. Às mulheres seriam representadas por signos de passividade: fraco, pequeno, passivo, submissão. Tais habitus foram, segundo o autor, tão bem disseminados que se naturalizaram para os dominados, criando um ambiente onde não há questionamentos em relação aos padrôes de conduta e das relaçóes que existem (BOURDIEU, 2012). É acerca desse inculcamento do babitus no dominado que Heleith Saffioti (2004, 
p. 35) se refere ao falar das mulheres machistas, entendendo que essas, assim como os homens, são socializadas dentro de um sistema patriarcal de gênero e poucas "questionam sua inferioridade social”.

É essa incorporação das relações de dominação que compõe o cenário de violência simbólica da qual as mulheres são vítimas. $\mathrm{O}$ conceito de violência simbólica também faz parte da linha boudiniana, sendo compreendido como uma forma de violência invisível entre um indivíduo/grupo dominante que exerce poder sobre outro indivíduo/grupo dominado, manifestando-se através das vias simbólicas da comunicação, tornando-a mais difícil de ser percebida e comprovada pela vítima (BOURDIEU, 1989).

Como apontado anteriormente, entender as relações de gênero no Brasil, implica em compreender, ainda que brevemente, tal cenário cultural. Buscando entender a construção da sociedade brasileira, Gilberto Freyre nos apresenta uma teoria de democracia racial, entendendo a miscigenação de europeus (portugueses, principalmente), os povos nativos e os escravos do continente africano como construtor desta. Para além disso, o autor discorre como a construção do Brasil se deu à sombra das grandes plantações de açúcar, onde a própria constituição da casa grande refletiria a organização social e política do Brasil.

Ao colocar a família patriarcal como "o grande colonizador do Brasil”, Freyre (2003), transporta as relaçóes familiares, sendo estas patriarcais, para a composição da identidade brasileira. Como entende Eni Samara (2002, p. 33), "o pátrio poder era, portanto, a pedra angular da família”. Ao transportar o pátrio poder para a composição da identidade brasileira, transporta-se o esquema de divisáo dos sexos onde cabe ao homem o babitus ativo, dominante e à mulher o babitus passivo, dominado, a tirania do ambiente privado, para o público.

Atualmente, autoras como Mariza Corrêa, tem contestado a posição generalizadora adotada por Freyre em sua obra ao falar do papel da família patriarcal na construção da sociedade brasileira. Corrêa entende que, embora não fosse hegemônico, o padrão familiar patriarcal funcionou como um instrumento disciplinador (CORREA, 1981). A
Igreja, no Brasil, sempre buscou implantar uma moral para controle social, usando a disciplina cristã como estratégia, onde o casamento, fundamentado na divisão bíblica dos sexos (o marido como o cabeça e a mulher devendo ser submissa), vai desempenhar papel de destaque.

Nesse sentido é possível observar o que Bourdieu evidencia em sua teoria acerca do papel que as instituiçóes têm no processo de reprodução das estruturas de dominação masculina. No caso brasileiro, a família patriarcal, ancorada na assimetria de poder entre homem e mulher, foi legitimada pela Igreja, sendo utilizada como mecanismo de controle social. Mais especificamente, mecanismo de controle das mulheres.

$O$ poder religioso se fez presente ainda na construção de uma categorização dos "tipos de mulheres" no imaginário coletivo e, consequentemente, na legislação penal. Lana Lima (2017) ao trabalhar as representações de gênero e sua relação com o Direito no Ocidente entende que há uma visão dicotômica acerca da mulher oriunda do pensamento cristão. À figura feminina seriam legados dois possíveis lugares: o de Maria, aquela que na tradição cristã seria a mãe de Jesus, ou de Eva, esposa de Adão que, após ser seduzida pelo Diabo a comer o fruto proibido, teria levado seu parceiro a fazer o mesmo. Transportadas para a esfera social, Maria representaria a mulher recatada, passiva, que se guarda sexualmente para o casamento, sendo o padrão desejável socialmente; enquanto Eva faria alusão à mulher traiçoeira, sedutora e imoral, simbolizando o comportamento indesejável. Dessa forma, "seu comportamento sexual determinaria, assim, a forma como deveria ser socialmente tratada" (LIMA, 2017, p. 9).

Embora a dominação masculina possa ser observada na maioria dos espaços sociais, as condiçôes históricas de construção destes podem exacerbar, ou não, tal dominação. O presente estudo tem como recorte espacial o Brasil, país latino americano e fruto da colonização portuguesa através do uso da mão de obra escrava africana e genocídio dos nativos. Compreender o processo de construção do Brasil e sua identidade foi fundamental para investigar como a dominação masculina se apresenta nas relações sociais dentro do país. 
O primeiro Código Penal republicano, acima citado, trazia uma diferenciação das vítimas de estupro, de acordo com a conduta desta, aspecto legal que já existia durante o Império. Segundo Daniela Colouris (2010), a graduação da pena existia, pois o crime produzia efeitos diferentes dependendo da vítima: contra a virgem/honesta, se afeta a sociedade, compromete o futuro de uma mulher moralmente correta; contra a prostituta/desonesta é apenas um crime contra a liberdade pessoal. O comportamento feminino era, e ainda é, ferramenta habilmente utilizada em tribunais para excluir e negar direitos às mulheres.

Hanna Arendt (2007), em seu estudo sobre poder e discurso, que surgem como simbólicos e atuam no campo político, entende que tal poder "não pode ser armazenado e mantido em reserva para casos de emergência”, pois, este, só existe em sua efetivação, do contrário, perde-se. A autora afirma que o "o poder só é efetivado enquanto a palavra e o ato não se divorciam [...] é o poder que mantem a existência da esfera pública, o espaço potencial da aparência entre homens que agem e falam" (ARENDT, 2007, p. 212). A dominação masculina destes homens se efetiva através de um discurso conciso, que é endossado pela mídia, e pelo sistema capitalista. Este poder simbólico no campo da ação não é imutável e configurado pela força, no entanto, se configura ao passo em que os homens agem juntos, como estrutura política e social no espaço físico e simbólico. Portanto, é este que preserva o status quo das classes dominantes e engendra os discursos de dominação presentes na sociedade patriarcal.

\section{Um estudo sobre O Cravo e a Rosa e Coisa Mais Linda e o contexto sócio histórico da mulher}

Com o advento da República na sociedade, as dinâmicas sociais se alteraram significativamente, por meio do capitalismo e, em consequência, do trabalho assalariado. Foi nesse período que movimentos mais organizados começaram a surgir ao redor do País, com ênfase na região sudeste, que era considerada a mais rica e desenvolvida. Estes movimentos estavam elencados no direito ao voto e na condição da mulher de um modo geral, como agente social, direito este que será o ponto chave das manifestaçốes na novela O Cravo e a Rosa (2000). No entanto, o papel da mulher seguiu sem alteraçóes significativas, pois, desse modo, sob a égide capitalista, ela era "duplamente explorada", isto é, além de ser "do lar", ela também sofria a exploração patronal, condição essa, ligada ao sistema capitalista (ALVES; PINTAGUY, 1987).

A primeira "onda" feminista, ou seja, a organização acentuada de um Movimento em prol dos direitos das mulheres foi no início do século XX, com as sufragistas. Essas mulheres buscavam o direito ao voto, e por meio da liderança de Bertha Lutz, no cenário brasileiro, esse Movimento foi o pioneiro e representou as mulheres eruditas de classe média, que em sua maioria haviam estudado em países mais desenvolvidos socioeconomicamente. Outra questão importante nas reivindicações feministas se referia à independência e à liberdade, e para tanto, constituíram um Partido Republicano Feminino. Este, por si, representou uma ruptura no status quo político brasileiro (PINTO, 2003).

Durante o processo de emancipação feminina no início do século $\mathrm{XX}$, o movimento feminista se fortaleceu através da luta pelo voto, que era considerada a grande bandeira das militantes, em conjunto com a luta pela igualdade de direitos em relação aos homens. A primeira onda feminista ficou marcada no Brasil justamente por essas questóes que à época eram relevantes e pertinentes às demandas $\mathrm{da}$ "mulher moderna" (PINTO, 2003).

$\mathrm{O}$ poder, nesse processo, surgiu com a representatividade efetiva da mulher na sociedade. No entanto, é impossível desassociá-lo das classes hegemônicas no início do século, ou seja, aos homens brancos, os quais detinham tal poder em relação à mulher no contexto social. $\mathrm{E}$, ainda que com o início do movimento feminista, a premência da luta pela igualdade padeceu entre os anos de 1900 e 1930 da política oligárquica brasileira, que, geralmente, era presidida e definida por, e para os homens. Este poder, e sua consequente dominação social, marginalizaram as mulheres que buscavam lutar pela igualdade de gênero, além de colocá-las como parte dos excluídos da história. O poder masculino na política brasileira é notável, e segundo Alves e Pintaguy (1987), ao passo em que a luta das 
mulheres pelo voto atingiu todas as classes as quais estas pertenciam, e durou mais de 40 anos no cenário nacional, sendo considerado um dos principais movimentos políticos do século $\mathrm{XX}$, a história não dedicou muitas páginas à questão do sufrágio.

Se nos livros de história a luta pelos direitos das mulheres não recebeu atenção proporcional, a mídia, por meio de novelas, buscou elucidar o telespectador sobre o Movimento Feminista, e seu significado em um contexto sócio-histórico. $\mathrm{O}$ discurso é necessário para que se possa compreender a relevância deste na sociedade, e as formas de poder que ele detém perante os indivíduos.

Michel Foucault (1996) considera que o discurso que determinada sociedade adota, e necessariamente inclui-se a mídia neste bojo, é

controlado, selecionado, organizado e redistribuído por certo número de procedimentos que tem por função conjurar seus poderes e perigos, dominar seu acontecimento aleatório, esquivar sua pesada e temível materialidade (FOUCAULT, 1996, p. 10).

Isto é, as práticas são ditadas de acordo com as classes dominantes, e organizadas para não alterar o status quo, ainda que pareça incluir outras demandas. No caso do discurso em um contexto sócio-histórico no qual esta pesquisa propóe realizar, tanto a novela O Cravo e a Rosa (2000 - 2001) que é ambientada na década de 1920, quanto a série Coisa Mais Linda (2019) que retrata a década de 1950, possuem elementos que nos permitem analisar o papel da mulher na sociedade à época em que se passavam.

A novela O Cravo e a Rosa foi lançada com a pauta que dividia, justamente, as feministas dos "machôes", o que reitera a divisão de classes que é abordada nos primeiros capítulos, principalmente. Em edição da Folha de SP, é possível entender o que a novela e suas personagens representaram no contexto social da década de 1920.

Nos anos de 1920 uma mulher não querer casar e brigar para ter os mesmos direitos dos homens era um grande escândalo [...] o que a feminista (Catarina) não esperava era encontrar Petrucchio, um machão caipira que está cheio de dividas e vê no casamento com a herdeira a única chance de se salvar do atoleiro (FOLHA DE SP, 2019).

O Cravo e a Rosa, transmitida no horário das 18h pela Rede Globo, entre 2000 e 2001, apresentou ao telespectador a realidade da mulher brasileira na década de 1920. Ainda que de forma bem-humorada, comprova a luta e o preconceito que as mulheres de classe média lidavam ao buscar a "igualdade dos sexos" e a luta pelo direito ao voto. Através da protagonização de Catarina (Adriana Esteves), feminista e filha do candidato à Prefeitura de São Paulo, o banqueiro Batista (Luís Melo), e Julião Petrucchio (Eduardo Moscovis), homem de modos rude, e consideravelmente machista, a novela faz da dicotomia macho-fêmea, homem-mulher um fator de relevância desde o início da novela. A relação com o feminismo está presente, sobretudo, no início da novela, e vai se enfraquecendo à medida em que as personagens feministas, tanto Catarina, como Lourdes (Carla Daniel) e Barbara (Virginia Cavendish), se apaixonam por homens, e novamente, reforçam a presença do status quo como fator determinante na manutenção da dominação masculina. Nas primeiras cenas já do primeiro capítulo, a premissa do folhetim é evidenciado, para tanto, há um protesto feminista, e um diálogo caracterizado por estereótipos patriarcais.

Protesto feminista: Abaixo a supremacia dos homens brancos. Pela igualdade dos sexos. Pelo voto. Pela igualdade dos sexos.

Petrucchio: Tem que andar na calçada, moça, não é na rua, não!

Lourdes: Dobre sua língua. É uma passeata pela igualdade dos sexos.

Petrucchio: Ah, a senhora é daquelas que acham que mulher é igual a homem.

Lourdes: Exatamente. Mulher é igual a homem e merece os mesmos direitos.

Petrucchio: Calma, moça brava. O homem e a mulher foram feitos pra fazer par. Não pra brigar, moça brava.

(O CRAVO e a Rosa (telenovela, capítulo 1). Direção de Dennis Carvalho e Walter Avancini. Rio de Janeiro: TV Globo, 2000-2001).

É fato que em seus escritos, Foucault (1996) tenha compreendido na sexualidade uma grande presença do Estado atuando como força absoluta nas 
relaçôes sociais e políticas, no entanto, é possível estabelecer um paralelo em relação ao gênero, e às mulheres, especificamente. As forças que atuam e atendem à "supremacia dos homens brancos" (como dito pelas feministas em $\mathrm{O}$ Cravo e a Rosa), oferecem discursos em torno das práticas do movimento feminista, do mesmo modo que regulam estes discursos.

Pois, como é demonstrado na fala do banqueiro Batista, em O Cravo e a Rosa, "uma mulher sem marido é uma faca sem ponta, uma galinha sem pé”, ou seja, a mulher da década de 1920, que organizava movimentos em torno da igualdade de gênero, deveria, para o bem das relações sociais, sobretudo, dentro da classe média, ser uma mulher casada, do contrário, seria marginalizada.

O casamento se faz presente como fator de relevância social que acentua a divisão de classes, mais uma vez, quando a personagem principal é questionada por não querer se casar.

Catarina - Olá, Jornalista. Vim com uma amiga trazer $\mathrm{o}$ artigo.

Jornalista Serafim - Dinorá. Nós fomos apresentados no dia da regata.

Dinorá - Sim. Estávamos eu, minha mãe e meu marido.

Jornalista Serafim - Marido, claro. Como poderia não ser casada com esse rosto de camafeu? Que homem ia permitir que ficasse solteira? A única beldade da cidade que insiste em ficar sem uma aliança no dedo é a senhorita Catarina. Culpa de nós, homens, que não conseguimos derreter seu coração.

Catarina - Meu coração não é banha de porco para ser derretido! Curioso, não, seu Serafim? Essa é a redação de uma revista feminina, no entanto, só vejo homens trabalhando.

Jornalista Serafim - Nós homens sabemos tudo que as mulheres gostam. Procuramos modelos de vestidos, receitas de culinária, pontos de bordado...ensinamos como tratar o maridinho.

Catarina - (sorriso irônico) então não sabe que as mulheres já estão em todas as profissóes? Temos até uma aviadora.

Jornalista Serafim - Cruz, credo. Eu jamais subiria em um avião pilotado por uma mulher. $\mathrm{O}$ avião corre o risco de cair enquanto ela estiver arrumando os cabelos.

Catarina - Francamente, senhor Serafim. Uma revista tem a obrigação de ensinar, educar, fazer reflexôes. Não fazem nada para a mulher poder pensar.

Jornalista Serafim - Pra que? Se o marido pensa por elas.

Catarina - Pois fique sabendo que a maioria dos homens tem repolho no lugar do cérebro. Bem servidas estariam as mulheres se dependessem deles. (O CRAVO e a Rosa (telenovela, capítulo 5). Direção de Dennis Carvalho e Walter Avancini. Rio de Janeiro: TV Globo, 2000-2001).

A novela se propõe a demonstrar, por meio de diálogos bem-humorados, uma realidade presente no Brasil do início do século: o poder simbólico masculino que se transforma em uma estrutura organizada e que age de acordo com a classe vigente no contexto político (Bourdieu, 1989). O Cravo e a Rosa reitera a pressão existente para que a mulher se case e constitua família, que foi umas das principais formas de dominação político-ideológica que o poder simbólico deteve no bojo social. Isto, através do discurso e da mídia, representada pela Revista Feminina na novela, como propagadora deste, que, novamente, se apresenta como regulador.

Catarina - Vocês já viram a Revista Feminina que está sendo lançada?

Lourdes - Eu já vi. Só fala de bordados e receitas. Um horror para nós feministas.

Barbara - Precisamos organizar um protesto contra essa revista.

Lourdes - Uma manifestação em repúdio.

(O CRAVO e a Rosa (telenovela, capítulo 3). Direção de Dennis Carvalho e Walter Avancini. Rio de Janeiro: TV Globo, 2000-2001).

O protesto segue contra o discurso apresentado na Revista Feminina, comandada pelo jornalista Serafim (João Vitti) que se demonstra a favor e defensor dos valores patriarcais vigentes.

Feministas - Homens no fogão. Mulheres na profissão!

Catarina - O senhor escreveu um artigo. Um, não. Vários. Dizendo que a mulher nasceu para lavar, passar, e cuidar do marido.

Jornalista Serafim - E para que mais serve uma mulher?

Catarina - Estou falando com um homem ou um jumento? 
Barbara - A mulher tem direito ao trabalho e ao salário.

Lourdes - A mulher não precisa de um marido. Ela sabe muito bem se virar sozinha. Não necessito de homem.

Barbara - Nem eu!

Jornalista Serafim - Catarina Batista, com todo respeito, pois, conheço a sua família. O que faz junto com esse bando de mulher macho?

Lourdes - Eu vou lhe processar! Eu exijo respeito. Eu sou uma donzela. O senhor está caluniando o movimento de emancipação da mulher.

Barbara - Eu poderia lhe dar uns tapas, para dobrar a sua língua. Companheiras, esse é mais um exemplo da dominação masculina (grifo nosso).

(O CRAVO e a Rosa (telenovela, capítulo 3). Direção de Dennis Carvalho e Walter Avancini. Rio de Janeiro: TV Globo, 2000-2001).

O discurso preconceituoso, que revela através das falas das personagens a dominação masculina, representa o poder simbólico que se legitimou na luta dos movimentos feministas no início do século, e que, exclui as mulheres da história. De acordo com Bourdieu (1989),

As diferentes classes e fracçôes de classes estão envolvidas numa luta propriamente simbólica para imporem a definição do mundo social mais conforme aos seus interesses, e imporem o campo das tomadas de posiçôes ideológicas reproduzindo em forma transfigurada o campo das posiçóes sociais. (BOURDIEU, 1989, p. 12).

Mais uma vez, sob um discurso que protege a estrutura social, é possível perceber a luta simbólica que existe, que demarca espaços masculinos e femininos, e que institucionaliza os papéis que cada um destes deve exercer. As falas das personagens demonstram como esse processo se dá na prática do cotidiano e na construção e sexualização dos espaços sociais.

As falas a seguir, demonstram a luta simbólica e o poder das classes hegemônicas que estruturam esse espaço social, e divide por gênero. Em uma tentativa de cortejar Catarina para estabelecer uma relação mais próxima, o Jornalista Serafim convida Catarina, mulher feminista, para escrever um artigo à sua Revista. No entanto, as ideias feministas, não são bem recebidas na Revista Feminina.

Jornalista Serafim - Eu não posso publicar esse artigo.

Catarina - Posso saber por que o senhor não aceita publicar?

Jornalista Serafim - A senhora diz coisas absurdas. Diz que o marido deve ajudar a lavar a louça da casa, a cozinha o feijão, e a encerar o assoalho.

Catarina - Por que só a mulher deve passar a vida cuidando da casa?

Jornalista Serafim - Ora, não há missão mais admirável do que a de rainha do lar.

Catarina - Escrava do lar. Isso sim!

(O CRAVO e a Rosa (telenovela, capítulo 3). Direção de Dennis Carvalho e Walter Avancini. Rio de Janeiro: TV Globo, 2000-2001).

Este discurso, de um homem branco de relativa influência social demonstra que existe um sexismo político-ideológico na construção das instituições sociais. Assim como, revela a diferença significativa que existe entre feminismo e feminino. A Revista Feminina é para as mulheres, no entanto, não é feita por mulheres. Ou seja, mantém as classes dominantes no poder e reforça essa divisão por meio do poder simbólico exercido pelo discurso. Para Foucault (1996, p. 10), “o discurso não é simplesmente aquilo que traduz as lutas e os sistemas de dominação, mas aquilo por que, pelo que se luta, o poder do qual queremos nos apoderar".

O discurso presente na novela, essencialmente nos primeiros capítulos demonstra que existe a intenção de subverter a ordem social vigente. No entanto, a medida que os capítulos transcorrem, observa-se o enfraquecimento do discurso feminista das mulheres, o que, por consequência assegura a manutenção das relaçôes sociais no início do século XX. Ou seja, a dominação masculina é legitimada e normatizada ao longo deste processo pelas personagens feministas.

A série da Netflix, Coisa Mais Linda (2019), retrata as mulheres na década de 1950, com quatro destas como protagonistas que vivem suas histórias ao longo de sete episódios, na primeira temporada. Todas as mulheres lidam com a desigualdade de gênero presente na sociedade de formas diferentes. Maria Luiza (Maria Casadaval) é mãe e esposa da classe média paulistana, que vai até o Rio de Janeiro 
procurar pelo marido, e percebe que foi abandonada por ele. Thereza (Mel Lisboa) é casada e é jornalista em um importante jornal carioca, ao que pese, ainda, o fato de não possuir filhos, o que a leva ser severamente criticado pela sogra. Ligia (Fernanda Vasconcelos) é ex-cantora, e esposa do candidato à Prefeitura do Rio de Janeiro, e Adélia (Patty de Jesus) é a única mulher solteira e pobre, além de ser negra e ter uma filha, e que consequentemente, possui uma profissão subalterna, como empregada doméstica.

É dessa maneira que as personagens são apresentadas ao público. Ou seja, diante da dominação masculina, e neste caso, com a presença da desigualdade social, vivenciada por Adélia, coisa que não é mostrada em $\mathrm{O}$ Cravo e a Rosa, cuja protagonista é da classe média paulistana.

Primeiramente, é preciso pontuar que entre as décadas de 1920 e 1950 houve algumas mudanças significativas em relação aos direitos das mulheres. $\mathrm{Na}$ década de 1950, elas poderiam votar e participar de instituições escolares e trabalhar. O sistema capitalista incluiu, dessa forma, algumas das demandas que o movimento feminista reivindicou no início do século XX. Isto acontece muito por conta da Segunda Guerra, entre 1939 e 1945, que valorizou sobremaneira a mão de obra feminina, para que a masculina pudesse participar das batalhas (ALVES, PINTANGUY, 1987)

E esse fato também afetou o Brasil, ainda que de forma menos proeminente. Entretanto, com o final $\mathrm{da}$ Guerra, os valores patriarcais que demarcaram territórios femininos e masculinos são reativados no bojo social. Como apontam Alves e Pitanguy,

As mensagens nos meios de comunicação enfatizam a imagem da 'rainha do lar'. Exacerbando-se a mistificação do papel de dona-de-casa, esposa e mãe. Novamente o papel da mulher é desvalorizado, tido como suplementar ao do homem. (ALVES; PITANGUY, 1987, p. 50).

Ou seja, entre as décadas de 1920 e 1950, houve retrocessos e avanços no papel da mulher na sociedade, de um modo geral. Tais exemplos são evidenciados nas falas das personagens em Coisa Mais Linda. Thereza possui a profissão de jornalista, o que seria um avanço em uma sociedade patriarcal, no entanto, para alguns, sobretudo, homens, era motivo de vergonha uma mulher trabalhar.
Nelson (marido de Thereza) - Vocês viram que minha linda e talentosa esposa conseguiu a primeira matéria de capa dela?
Thereza - Não foi nada demais!
Augusto (irmão de Nelson e marido de Ligia) - Você tá precisando de dinheiro, Nelsinho?
Nelson - Como assim?
Augusto - Então por que você ta deixando sua mulher trabalhar? Tá certo, isso?
Nelson - Você e eu temos visões muito diferentes sobre o que é certo e errado. Thereza é dona de si, não vou dizer pra ela o que ela deve ou não fazer.
(COISA mais linda (Temporada 1, episódio 4). Criadores: Giuliano Credoni, Heather Roth, Pati Corso. Brasil: Netflix. 2019).

A dominação masculina, tanto simbólica quanto econômica, reitera o poder das classes dominantes e a divisão que se estabelece a partir disso. É desse modo que o pai de Malu exerce controle sobre a filha, ainda que esta se mostre subversiva ao domínio do pai. A mulher, como sombra do homem, buscava liberdade, inclusive, para afirmar sua identidade.

Uma das aproximações mais evidentes entre O Cravo e a Rosa e Coisa Mais Linda é o fato de que as Revistas, apresentadas nas tramas, que atuam como meio de comunicação em ambas as obras, são dirigidas e feitas por homens para mulheres, respectivamente. A grande diferença, e que também revela algumas das mudanças sociais que ocorreram entre os períodos, é que em Coisa Mais Linda, há, pelo menos, uma mulher na redação, e esta é Thereza. No entanto, ela enfrenta os efeitos de uma sociedade patriarcal, principalmente quando pede a contratação de outra mulher.

Paulo Sergio (redator chefe) - Por favor, Thereza, não é tão difícil, assim. Não precisa ser gênio pra escrever como uma mulher.

Thereza - Eu tô te falando, Paulo Sergio. Eu entrevistei mais de oito rapazes, e nenhum deles têm a menor intimidade com o mundo das mulheres.

Paulo Sergio - Não existe essa história de "mundo das mulheres". Só existe um mundo, e definitivamente é o nosso! 
Thereza - Agora me diz: Por que a gente precisa de mais um homem na redação?

Paulo Sergio - Simples: biologia. Homem é mais focado, mais profissional, menos emotivo. Se você fosse homem, a gente nem teria essa conversa. A gente sabe cumprir regras.

(COISA mais linda (Temporada 1, episódio 5). Criadores: Giuliano Credoni, Heather Roth, Pati Corso. Brasil: Netflix. 2019).

Novamente, é possível perceber que o homem que comanda a redação demonstra atitudes que corroboram para a manutenção da estrutura social e da organização dividida entre espaços masculinos e femininos. Em outro diálogo entre os dois, Thereza utiliza-se de outros mecanismos para convencer o chefe a contratar uma mulher para a redação.

Thereza - Eu te trouxe duas opções: o Lucas que é muito experiente. Já trabalhou nas melhores revistas do mercado. E tem a Hello, que tem bastante vivência no mundo da moda.

Paulo Sergio - Você tem alguma dúvida de quem eu vou escolher?

Thereza - Nenhuma. Mas os homens são mais caros. Essa garota te custaria cinco vezes menos.

Paulo Sergio - É... acho que não faria mal ter mais um rabo de saia pra decorar o ambiente.

(COISA mais linda (Temporada 1, episódio 5).

Criadores: Giuliano Credoni, Heather Roth, Pati

Corso. Brasil: Netflix. 2019).

As disputas entre homens e mulheres, principalmente no trabalho, são interessantes e permitem uma análise de como as forças sistêmicas atuam entre classes. Thereza, por meio de um discurso inteligente não procura o conflito, mas sim, convencer o chefe de que ter outra mulher na redação atende aos interesses dele, e não dela. Novamente, isso é exemplificado em outro momento.

Paulo Sergio - Que merda é essa? Por que isso não passou por mim?

Thereza - Porque o prazo 'tava' apertado. Você viu a chuva de cartas das leitoras elogiando?

Paulo Sergio - Isso aqui é pior do que jogar gasolina num incêndio. Nosso público não tá pronto 'pra' isso!

Hello - Elas estão pedindo por isso.
Paulo Sergio(?) - Eu falei com você? Some daqui. Xispa. Thereza, ela não é o tipo de mulher que essa revista representa!

(COISA mais linda (Temporada 1, episódio 5. Criadores: Giuliano Credoni, Heather Roth, Pati Corso. Brasil: Netflix. 2019).

Assim como em O Cravo e a Rosa, quando o jornalista Serafim diz a Catarina que seu artigo não pode ser publicado, pois seria uma afronta à sociedade, Paulo Sergio, em A Coisa Mais Linda, adota o mesmo discurso, no entanto, com um artigo já publicado, e reverenciado pelas mulheres leitoras. Foucault (1996) entende este tipo de dominação como um poder que regula as falas e manifestações individuais.

Desta vez, não se trata de dominar os poderes que eles têm, nem de conjurar os acasos de sua aparição; trata-se de determinar as condiçóes de seu funcionamento, de impor aos indivíduos que os pronunciam certo número de regras e assim de não permitir que todo mundo tenha acesso a eles (FOUCAULT, 1996, p. 37).

Outra similaridade com O Cravo e a Rosa é o fato de que na alta sociedade, ser uma mulher casada é fundamental para a hierarquia social. No entanto, aí também reside uma diferença; se em $\mathrm{O}$ Cravo e a Rosa, Catarina se casa com Petrucchio e silencia seu discurso feminista, Malu (que era casada), pelo contrário, não cede.

\footnotetext{
Adhemar - Sobre o coquetel de hoje a noite...

Malu - Eu não vou, pai!

Adhemar - Você entende a sorte que seria se um rapaz como esse aceitasse se casar com você?

Malu - Casar?

Adhemar - Está na hora de voltar pra realidade. Você precisa arrumar um novo marido. Decente, dessa vez.

(COISA mais linda (Temporada 1, episódio 6). Criadores: Giuliano Credoni, Heather Roth, Pati Corso. Brasil: Netflix. 2019).
}

Tanto O Cravo e a Rosa, como Coisa Mais Linda demonstram que houve algumas mudanças entre a década de 1920 e 1950, no entanto, revelam que o discurso, e consequentemente, as práticas sociais não alteraram significativamente a realidade 
feminina. Ainda que, como as falas demonstram, tenha iniciado no século $\mathrm{XX}$ transformaçóes importantes pelos direitos e pela igualdade nestes. As aproximações entre os discursos são fundamentais para entender as diferenças e similaridades entre as produções.

\section{Considerações finais}

O que O Cravo e a Rosa (2000 - 2001) demonstrou em seu discurso foi que na primeira metade do século XX, no Brasil, a luta foi marcada pelo movimento de mulheres que buscavam a ampliação de seus direitos, sendo o direito ao voto o carro chefe das demandas. Entre 1920 e 1960, houve avanço nesse sentido: o voto feminino, conquistado em 1932, a participação em instituições escolares e no mercado de trabalho. No entanto, persistiram obstáculos e discursos que procuravam cercear a continuidade da emancipação feminina numa sociedade patriarcal.

Tal discurso se faz presente nas obras analisadas no presente trabalho, através das falas de algumas das personagens masculinas. Nas falas desses personagens há uma recorrente ideia de que à mulher não cabe um espaço próprio no mercado de trabalho, independência financeira ou mesmo identidade emancipada de uma figura masculina.

Ainda que, desde 1930, tenham ocorrido significantes avanços nos direitos femininos, ficou evidenciado pelas obras, contudo, a divisão de espaços e arquétipos característicos entre homens e mulheres, ou seja, a manutenção da dominação masculina no habitus das relações sociais.

\section{Referências}

ALVES, Branca, M. e PINTANGUY, Jacqueline. O que é feminismo? Ed. Abril cultural e Brasiliense, 1987.

ARAÚJO, Emanuel. O teatro dos vícios, Transgressão e transigência na sociedade urbana colonial. 2 ed. Livraria José Olympio Editora S.A. Rio de Janeiro, 1993.
ARENDT, Hanna, A Condição Humana, tradução Roberto Raposo, ed. Forense Universitária, Rio de Janeiro, 2007.

BOURDIEU, Pierre. A Dominação Masculina. 11a ed. Rio de Janeiro: Bertrand Brasil, 2012.

BOURDIEU, Pierre. O poder simbólico. Rio de Janeiro: Bertrand Brasil, 1989.

COISA mais linda (Temporada 1). Criadores: Giuliano Credoni, Heather Roth, Pati Corso. Brasil: Netflix. 2019. Disponível em: https://www.netflix.com/title/80208298.

Acesso em: 10 dez. 2019.

COULOURIS, Daniella Georges. A Desconfiança em Relação à Palavra da Vitima e o Sentido da Punição em Processos Judiciais de Estupro. 2010, 242 f. Tese (Doutorado em Sociologia) Faculdade de Filosofia, Letras e Ciências Humanas, Universidade de São Paulo. São Paulo.

CORRÊA, Mariza. Repensando a família patriarcal brasileira. Cadernos de pesquisa, n. 37, p. 5-16, 2013. Disponível em:

http://publicacoes.fcc.org.br/ojs/index.php/cp/artic le/view/1590. Acesso em 8 fev. 2020.

FOUCAULT, Michel, A Ordem do Discurso, tradução Laura de Almeida Fraga, Ed. Loyola, São Paulo, 1996.

FREYRE, Gilberto. Casa Grande \& Senzala: formação da família brasileira sob o regime da economia patriarcal. 48 ed. São Paulo: Global, 2003.

GEERTZ, Clifford. A Interpretação das Culturas. 1 ed. 13 reimpr. Rio de Janeiro: LTC, 2008. 
LIMA, Lana Lage da Gama. Cultura do Estupro, Representaçôes de Gênero e Direito. Language and Law / Linguagem e Direito, v. 4, n. 2, 2017, p. 7-18. Disponível em:

https://ler.letras.up.pt/uploads/ficheiros/15912.pdf Acesso em: 27 jan. 2020.

O CRAVO e a Rosa (telenovela). Direção de Dennis Carvalho e Walter Avancini. Rio de Janeiro: TV Globo, 2000.

PERROT, Michelle. Os excluídos da História: operários, mulheres e prisioneiros. Rio de Janeiro: Paz e Terra, 1988.

PRIORE, Mary del. A mulher na história do Brasil, ed. Contexto, São Paulo, 1995.

PINTO, Celia R. J., Uma história do feminismo no Brasil, Ed. Fundação Perseu Abramo, São Paulo, 2003.

SAFFIOTI, Heleieth I. B. Gênero, patriarcado, violência. São Paulo: Fundação Perseu Abramo, 2004.

SAMARA, Eni de Mesquita. O Que Mudou na Família Brasileira?: da Colônia à Atualidade. Psicol. USP, São Paulo, v. 13, n. 2, p. 27-48, 2002. Disponível em: http://www.scielo.br/scielo.php?pid=S0103 $65642002000200004 \&$ script $=$ sci_abstract $\&$ tlng $=$ pt Acesso em: 15 dez. 2019.

TBÉBAUD, Françoise, História de las mujeres siglo XX. Distribuidora y Editora Aguilar, Altea, Taurus, Alfaguara, S. A., 1993. 